\title{
Plasma RANTES, IL-10, and IL-8 levels in non-small-cell lung cancer patients treated with EGFR-TKIs
}

Kanako Umekawa ${ }^{1 \dagger}$, Tatsuo Kimura ${ }^{1{ }^{*}}$, Shinzoh Kudoh' ${ }^{1}$, Tomohiro Suzumura ${ }^{1}$, Takako Oka ${ }^{1}$, Misato Nagata ${ }^{1}$, Shigeki Mitsuoka ${ }^{1}$, Kuniomi Matsuura ${ }^{1}$, Toshiyuki Nakai ${ }^{1}$, Naruo Yoshimura ${ }^{1}$, Yukimi Kira ${ }^{2}$ and Kazuto Hirata ${ }^{1}$

\begin{abstract}
Background: Epidermal growth factor receptor (EGFR) tyrosine kinase inhibitors (TKIs), routinely used to treat advanced non-small-cell lung cancer (NSCLC) patients with activated EGFR mutations, are associated with excellent response and improved performance status. Recently, pro-inflammatory cytokines, such as regulated upon activation normal T cell expressed and secreted (RANTES), interleukin (IL)-10 and IL-8 have been proposed as mediators of cancer development. EGFR-TKIs have been found to affect this network of pro-inflammatory cytokines.

Methods: EGFR-TKIs (erlotinib, 150 mg/day; and gefitinib, 250 mg/day) were administered once per day. Treatment was continued until disease progressed or the patient developed intolerable symptoms of toxicity, or withdrew his/her consent for study participation. The treatment was a part of standard care. We investigated the correlation between plasma pro-inflammatory cytokines (including plasma RANTES, IL-10, and IL-8) levels and clinical outcomes following EGFR-TKI treatment in lung cancer patients. Pro-inflammatory cytokine levels were evaluated at diagnosis and on treatment day 30 after the first administration of EGFR-TKIs.

Results: Overall, 33 patients were enrolled. Plasma pro-inflammatory cytokine levels were determined for all patients at diagnosis. Plasma samples from 26 patients were obtained on treatment day 30. High level of RANTES at diagnosis was associated with severe general fatigue $(P=.026)$. Low level of RANTES at diagnosis was significantly associated with long-term survival $(P=.0032)$. Percent decrease change of IL-10 was associated with severity of rash $(\mathrm{P}=.037$ ). The plasma IL-8 level on treatment day 30 (median, $5.48 \mathrm{pg} / \mathrm{mL}$; range, $0.49-26.13 \mathrm{pg} / \mathrm{mL}$ ) was significantly lower than the level at diagnosis (median $10.45 \mathrm{pg} / \mathrm{mL} ; 3.04-54.86 \mathrm{pg} / \mathrm{mL} ; \mathrm{P}=.021$ ).

Conclusions: These results suggest that EGFR-TKls may suppress systemic inflammation and promote tumor shrinkage. The network of pro-inflammatory cytokines was affected by EGFR-TKI treatment for NSCLC. In addition, the clinical outcomes of EGFR-TKI treatment were influenced by the status of the plasma pro-inflammatory cytokines at diagnosis.
\end{abstract}

Keywords: NSCLC, EGFR-TKIs, RANTES, IL-8, IL-10

\footnotetext{
*Correspondence: kimutats@med.osaka-cu.ac.jp

${ }^{\dagger}$ Equal contributors

'Department of Respiratory Medicine, Graduate School of Medicine, Osaka

City University, 1-4-3 Asahi-machi, Abeno-ku, Osaka 545-8585, Japan

Full list of author information is available at the end of the article
} 


\section{Background}

Cancer is associated with systemic inflammation driven by multiple pro-inflammatory cytokines [1]. The network of pro-inflammatory cytokines such as regulated upon activation normal T-cell expressed and secreted (RANTES), interleukin (IL)-10, and IL-8 have been proposed as mediators of cancer development $[1,2]$. Pro-inflammatory cytokines play roles in catabolism, gluconeogenesis, and acute-phase protein production [1]. They also play protective roles during the first stages of inflammation; however, persistent continuation has deleterious effects.

Gefitinib and erlotinib are orally administered epidermal growth factor receptor (EGFR) tyrosine kinase inhibitors (TKIs) used for the treatment of non-small-cell lung cancer (NSCLC) in patients with activated mutations of the EGFR gene [3-6]. Unlike treatment with cytotoxic agents, EGFR-TKIs are associated with excellent response rates, prolonged survival, low numbers of adverse hematological events, and improved quality of life. EGFR signaling is triggered by the binding of EGF and EGF-like growth factors, resulting in the homodimerization of EGFR molecules or heterodimerization of EGFR with other closely related receptors such as c-erbB2 [7]. EGF-stimulated EGFR phosphorylation [8] promotes cancer cell proliferation through the downstream phosphoinositide 3-kinase (PI3K)/Akt and extracellular signal-regulated kinase (ERK1/2) pathways [9]. PI3K/Akt and ERK1/2 pathways are activated in lung cancer [10] and are closely associated with cancer cell proliferation $[11,12]$.

RANTES is a known chemotactic cytokine that is produced by many cell types, including T-lymphocytes, monocytes, platelets, eosinophils, epithelial cells, dendritic cells, and mast cells [13]. RANTES, which is transcribed and secreted not only by $\mathrm{T}$ cells, other inflammatory cells, and stromal cells, but also tumor cells and nonmalignant bronchial epithelium, is involved in immunoregulatory and inflammatory processes [14]. RANTES has been used as a prognostic indicator in both breast and cervical cancers and high levels of RANTES in these malignancies correlates with a poor outcome $[14,15]$. RANTES in breast carcinoma is associated with invasion, metastasis, and poor clinical survival $[16,17]$. Protein kinases $C(P K C) \alpha$ and $\beta$ have been shown to affect tumor progression and malignant phenotype $[18,19]$. PKC $\alpha$ plays an obligatory role in EGFR transactivation and signaling to ERK1/2 activation [20-22]. PKC $\alpha$-dependent EGFR transactivation may contribute to the development and maintenance of the androgen-refractory phenotype in advanced prostate cancer [22]. PKC $\alpha / \beta$ activator 12-O-tetradecanoylphorbol-13acetate (TPA) only induces IL-8 expression, whereas both inhibit tumor necrosis factor (TNF)- $\alpha$ induced RANTES expression [2].

IL-10, an immunoregulatory component in the cytokine network, is mainly expressed by monocytes, macrophages,
T cells, and normal and neoplastic B cells [23]. IL-10 is associated with tumor malignancy via immune escape. IL-10 promotes tumor malignancy by promoting $\mathrm{T}$ cell apoptosis and tumor cell survival [24]. Marked decrease in plasma IL-10 levels accompanies marked increase in RANTES levels in patients with severe, treatmentresistant atopic dermatitis [25]. Previous reports have shown that IL-10 has different prognostic significance in early and late stage lung cancer patients [23]. Absence of IL-10 expression is associated with poor outcome in stage I NSCLC, whereas presence of IL-10 positive macrophages in late stage NSCLC is an indicator of poor prognostic outcome. Moreover, persistence of EGFR and IL-10 in the blood of colorectal cancer patients after surgery indicates a high risk of relapse in patients [26].

IL-8 is a cytokine of the CXC chemokine family and acts as a ligand for 2 G-protein coupled receptors [7]. In addition to its role in neutrophil recruitment and activation, IL- 8 is thought to be involved in a wide variety of other processes such as angiogenesis and the formation of metastases in lung cancer $[27,28]$. EGF has been demonstrated to initiate the release of IL-8 from bronchial epithelial and lung cancer cells $[9,29,30]$. ERK phosphorylation is associated with IL-8 expression in airway epithelium cells [31,32]. An in vitro study has shown that the ability of IL-8 to increase cell proliferation is blocked by an inhibitor of EGFR tyrosine kinase [7]. IL-8 is positively regulated by EGFR signaling, whereas EGFR inhibitors block IL-8 expression [33]. In the nude mice model, treatment with monoclonal antibody C225, directed against the EGFR, inhibits $\mathrm{mRNA}$ and protein production of IL-8 [34].

EGFR-TKIs are thought to partially affect these cancer related pro-inflammatory cytokine networks. To test this hypothesis, we investigated the correlation between plasma pro-inflammatory cytokine levels and clinical outcomes following EGFR-TKI treatment in lung cancer patients. Pro-inflammatory cytokine levels were evaluated at diagnosis and on treatment day 30 after the first administration of EGFR-TKIs.

\section{Methods}

\section{Patients}

Eligible patients had pathologically confirmed advanced NSCLC that recurred after 1 or 2 prior chemotherapies. Each patient was required to meet the following criteria: adequate organ function, performance status (PS) of 0-2, and no other active malignancies. Mutations in the tyrosine kinase domain (exons 18-21) of EGFR were identified using the peptide nucleic acid (PNA) clamp polymerase chain reaction (PCR) assay [35]. Written informed consent was obtained from all patients. This study was approved by the Osaka City University Institutional Review Board (approval number: 1377). 


\section{Treatment, response, and clinical outcome}

EGFR-TKIs (erlotinib, $150 \mathrm{mg} /$ day; and gefitinib, $250 \mathrm{mg} /$ day) were administered once per day. Treatment was continued until disease progressed or the patient developed intolerable symptoms of toxicity, or withdrew his/her consent for study participation. The treatment was a part of standard care. The objective responses of each lesion examined were assessed every 4 weeks following commencement of EGFR-TKIs administration by using the Response Evaluation Criteria in Solid Tumors, version 1.0 [36]. Toxicity was graded according to the National Cancer Institute Common Toxicity Criteria Version 3.0 [37]. EGFR-TKIs related nonhematologic toxicities of grade 3 and 4 were managed by reducing the dose of EGFR-TKIs. The progression-free survival (PFS) or overall survival (OS) was calculated from the start of EGFR-TKI treatment to the date of disease progression or death.

Table 1 Patient characteristics $(n=33)$

\begin{tabular}{|c|c|c|}
\hline Characteristics & Number & \\
\hline \multicolumn{3}{|l|}{ Age, years } \\
\hline Median (range) & 67 & $(54-86)$ \\
\hline \multicolumn{3}{|l|}{ Sex } \\
\hline Male/female & $18 / 15$ & \\
\hline \multicolumn{3}{|l|}{ Performance status } \\
\hline $0 / 1 / 2$ & $2 / 28 / 3$ & \\
\hline \multicolumn{3}{|l|}{ Clinical stage } \\
\hline III/IV & $6 / 27$ & \\
\hline \multicolumn{3}{|l|}{ Histology } \\
\hline $\mathrm{Ad} / \mathrm{Sq} / \mathrm{La}$ & $29 / 3 / 1$ & \\
\hline \multicolumn{3}{|l|}{ EGFR mutation status } \\
\hline Ex18 del/ Ex19 del/ Ex21L858R & $1 / 9 / 9$ & \\
\hline Negative & 9 & \\
\hline Unknown & 5 & \\
\hline \multicolumn{3}{|l|}{ Brinkman index } \\
\hline Median (range) & 370 & $(0-3840)$ \\
\hline \multicolumn{3}{|l|}{ Body mass index, $\mathrm{Kg} / \mathrm{m}^{2}$} \\
\hline Median (range) & 23.0 & $(16.0-29.8)$ \\
\hline \multicolumn{3}{|l|}{ Concomitant disease } \\
\hline rheumatoid arthritis & 1 & \\
\hline diabetes mellitus & 6 & \\
\hline hyperlipidemia & 6 & \\
\hline hypertension & 17 & \\
\hline \multicolumn{3}{|l|}{ Treatment line } \\
\hline 1st/2nd/more & 3/19/11 & \\
\hline
\end{tabular}

EGFR, Epidermal growth factor receptor; Ad, Adenocarcinoma; Sq, Squamous cell carcinoma, La, Large-cell carcinoma; Ex, Exon; del, Deletion.

\section{Analyses of plasma pro-inflammatory cytokines}

Plasma samples were collected at diagnosis and on treatment day 30 . Venous blood $(7 \mathrm{~mL})$ was collected in EDTA (anticoagulant)-containing tubes and immediately centrifuged at $3000 \mathrm{rpm}$ for $15 \mathrm{~min}$. Plasma samples were frozen at $-80^{\circ} \mathrm{C}$ until analysis. Plasma RANTES, IL-10, and IL-8 levels were measured using the Luminex 200× PONENT system (Milliplex MAP kit; Millipore, Billerica, MA, USA), according to the manufacturer's instructions. Plasma RANTES, IL-10, and IL-8 levels were estimated as previously reported [38]. Briefly, $25 \mu \mathrm{L}$ of plasma was incubated with antibody-linked beads overnight at $4^{\circ} \mathrm{C}$, rinsed twice with the washing solution, and incubated for 1 hour with biotinylated secondary antibodies. Data acquisition using the Luminex system was performed after a final incubation with streptavidinphycoerythrin for 30 minutes. The minimum detectable concentrations of plasma RANTES, IL-10, and IL-8 levels were $69.00,21.50$, and $13.25 \mathrm{pg} / \mathrm{mL}$, respectively. All samples were assayed in duplicate.

\section{Statistical analyses}

All values are expressed as the median and range. Statistical comparisons of pro-inflammatory cytokine levels before and after treatments were performed using the Wilcoxon signed-ranks test. The association between the plasma pro-inflammatory cytokine levels at diagnosis and the effects of EGFR-TKI treatments was assessed using the Mann-Whitney test. The association between the changes of plasma pro-inflammatory cytokine levels and the effects of EGFR-TKI treatments was also assessed with Mann-Whitney test. Stepwise multiple regression analysis was performed to evaluate the independent relationship of overall survival with age, sex, stage IIIb or IV, EGFR mutation status, plasma RANTES, IL-10, and IL-8 levels at diagnosis. Two-tailed P values $<0.05$ were considered significant. A box plot provides information about the median, variability, and outliers of data distribution. The horizontal line within each box indicates the sample median. The plot consists of a box that extends from the 25th quantile to the 75 th quantile. The box lines that extend from each end to the outermost data point that falls within the distances were computed as follows: 1 st quartile $+1.5^{*}$ (interquartile range) and 3rd quartile $+1.5^{*}$ (interquartile range). Data points outside these computed ranges were considered outliers. All statistical analyses were carried out using the JMP 8.0 statistical program (SAS Institute, Inc., Cary, NC, USA).

\section{Results}

\section{Patient characteristics}

Thirty-three patients were enrolled between September 2008 and October 2009. Adequate plasma samples could not be obtained for analyses from 7 patients on treat- 
Table 2 Summary of plasma pro-inflammatory cytokines levels at diagnosis in patients with NSCLC

\begin{tabular}{|c|c|c|c|c|c|c|c|c|}
\hline Case & Histrogical type & EGFR mutation status & Brinkman index & Treatment agent & Response & IL-8 (ng/mL) & IL-10 (ng/mL) & RANTES (pg/ml) \\
\hline 1 & $\mathrm{Ad}$ & Ex21 L858R & 900 & gefitinib & $P R$ & 5.79 & 1.67 & 2 \\
\hline 2 & $\mathrm{Ad}$ & Ex21 L858R & 0 & erlotinib & PR & 3.33 & 94.2 & 1.41 \\
\hline 3 & $\mathrm{Ad}$ & Ex19 del & 0 & erlotinib & PR & 4.09 & 126 & 2.13 \\
\hline 4 & $\mathrm{Ad}$ & Ex21 L858R & 0 & gefitinib & PR & 3.92 & 18.1 & 1.85 \\
\hline 5 & $\mathrm{Ad}$ & Ex21 L858R + Ex19 del & 370 & erlotinib & PR & 21.9 & 1.23 & 2.11 \\
\hline 6 & $\mathrm{Ad}$ & Ex19 del & 0 & erlotinib & PR & 7.05 & 1.37 & 2.56 \\
\hline 7 & $\mathrm{Ad}$ & Ex19 del & 0 & gefitinib & PR & 4.82 & 1.59 & 2.02 \\
\hline 8 & $\mathrm{Ad}$ & Ex21 L858R & 1640 & gefitinib & PR & 54.9 & 2.7 & 2.38 \\
\hline 9 & $\mathrm{Ad}$ & negative & 400 & erlotinib & SD & 34.9 & 3.39 & 3.66 \\
\hline 10 & $\mathrm{Ad}$ & negative & 0 & erlotinib & SD & 27.1 & 4.94 & 2.25 \\
\hline 11 & $\mathrm{Ad}$ & unknown & 1800 & erlotinib & SD & NE & $N E$ & $\mathrm{NE}$ \\
\hline 12 & $\mathrm{Sq}$ & Ex19 del & 3840 & gefitinib & SD & 12.6 & 1.1 & 1.98 \\
\hline 13 & $\mathrm{Ad}$ & Ex19 del & 30 & erlotinib & SD & 5.27 & 0.69 & 2.66 \\
\hline 14 & $\mathrm{Ad}$ & Ex19 del & 0 & erlotinib & SD & 10.5 & 0.85 & 2.5 \\
\hline 15 & $\mathrm{Ad}$ & unknown & 300 & erlotinib & SD & 7.69 & 2.61 & 1.7 \\
\hline 16 & La & negative & 2080 & erlotinib & SD & NE & $N E$ & $\mathrm{NE}$ \\
\hline 17 & $\mathrm{Sq}$ & Ex21 L858R & 750 & erlotinib & SD & 11.6 & 56.3 & 3.06 \\
\hline 18 & $\mathrm{Ad}$ & unknown & 600 & erlotinib & SD & 13.7 & 1.1 & 2.82 \\
\hline 19 & $\mathrm{Ad}$ & Ex21 L858R & 0 & erlotinib & SD & 20.6 & 11.6 & 0.783 \\
\hline 20 & $\mathrm{Ad}$ & Ex19 del & 0 & erlotinib & SD & 14.8 & 2.07 & 2.02 \\
\hline 21 & $\mathrm{Ad}$ & Ex21 L858R + Ex19 del & 0 & gefitinib & SD & 3.04 & 1.3 & 1.76 \\
\hline 22 & $\mathrm{Ad}$ & Ex19 del & 200 & gefitinib & SD & 10.9 & 1.59 & 1.91 \\
\hline 23 & $\mathrm{Sq}$ & unknown & 1560 & erlotinib & PD & NE & $\mathrm{NE}$ & NE \\
\hline 24 & $\mathrm{Ad}$ & negative & 1080 & erlotinib & PD & 25.2 & 8.15 & 1.57 \\
\hline 25 & $\mathrm{Ad}$ & unknown & 0 & erlotinib & PD & NE & $\mathrm{NE}$ & NE \\
\hline 26 & $\mathrm{Ad}$ & Ex18 G719A & 2000 & erlotinib & PD & 11.6 & 4.48 & 3.12 \\
\hline 27 & $\mathrm{Ad}$ & unknown & 1410 & erlotinib & PD & NE & $\mathrm{NE}$ & $\mathrm{NE}$ \\
\hline 28 & $\mathrm{Ad}$ & Ex19 del & 1000 & gefitinib & PD & 9.44 & 2.25 & 2.89 \\
\hline 29 & $\mathrm{Ad}$ & negative & 1100 & erlotinib & PD & 56.3 & 5.63 & 2.16 \\
\hline 30 & $\mathrm{Ad}$ & negative & 2000 & erlotinib & PD & 15.6 & 0.85 & 0.292 \\
\hline 31 & $\mathrm{Ad}$ & negative & 825 & erlotinib & PD & 8.27 & 1.59 & 2.13 \\
\hline 32 & $\mathrm{Ad}$ & Ex21 L858R & 0 & erlotinib & PD & 5.34 & 7.05 & 1.7 \\
\hline 33 & $\mathrm{Ad}$ & negative & 1680 & erlotinib & PD & 57.7 & 1.63 & 2.06 \\
\hline
\end{tabular}

NSCLC, Non-small-cell lung cancer; Ad, Adenocarcinoma; Sq, Squamous cell carcinoma; La, Large-cell carcinoma; Ex, Exon; del, Deletion; $P R$, Partial response; SD, stable disease; PD, Progression disease; IL-8, Interleukin-8; IL-10, Interleukin-10; RANTES, Regulated upon activation normal T-cell expressed and secreted.

ment day 30. EGFR mutation status was positive in 19 patients, negative in 9, and unknown in 5. Initially, none of the patients with EGFR mutations had the secondary T790M mutation. The numbers of patients with concomitant diseases and drugs, which influence cytokine levels, were as follows: chronic rheumatoid arthritis (1), diabetes mellitus (6), hyperlipidemia (6), and hypertension (17). No patient had an infectious disease. The patient population profile is provided in Table 1.

\section{Clinical outcomes}

The rate of rash, diarrhea, appetite loss, general fatigue, and liver dysfunction of all grades was 97.0\%, $30.3 \%$, 48.5\%, 50.0\%, and 38.5\%, respectively. Response to EGFR-TKI treatments included partial response (PR) in 8 cases $(24 \%)$, stable disease (SD) in $14(42 \%)$, and progressive disease (PD) in 11 (33\%). Patients in all of 8 PR cases, 8 of 14 SD cases, and 3 of 11 PD cases showed EGFR mutations. On treatment day 30, 


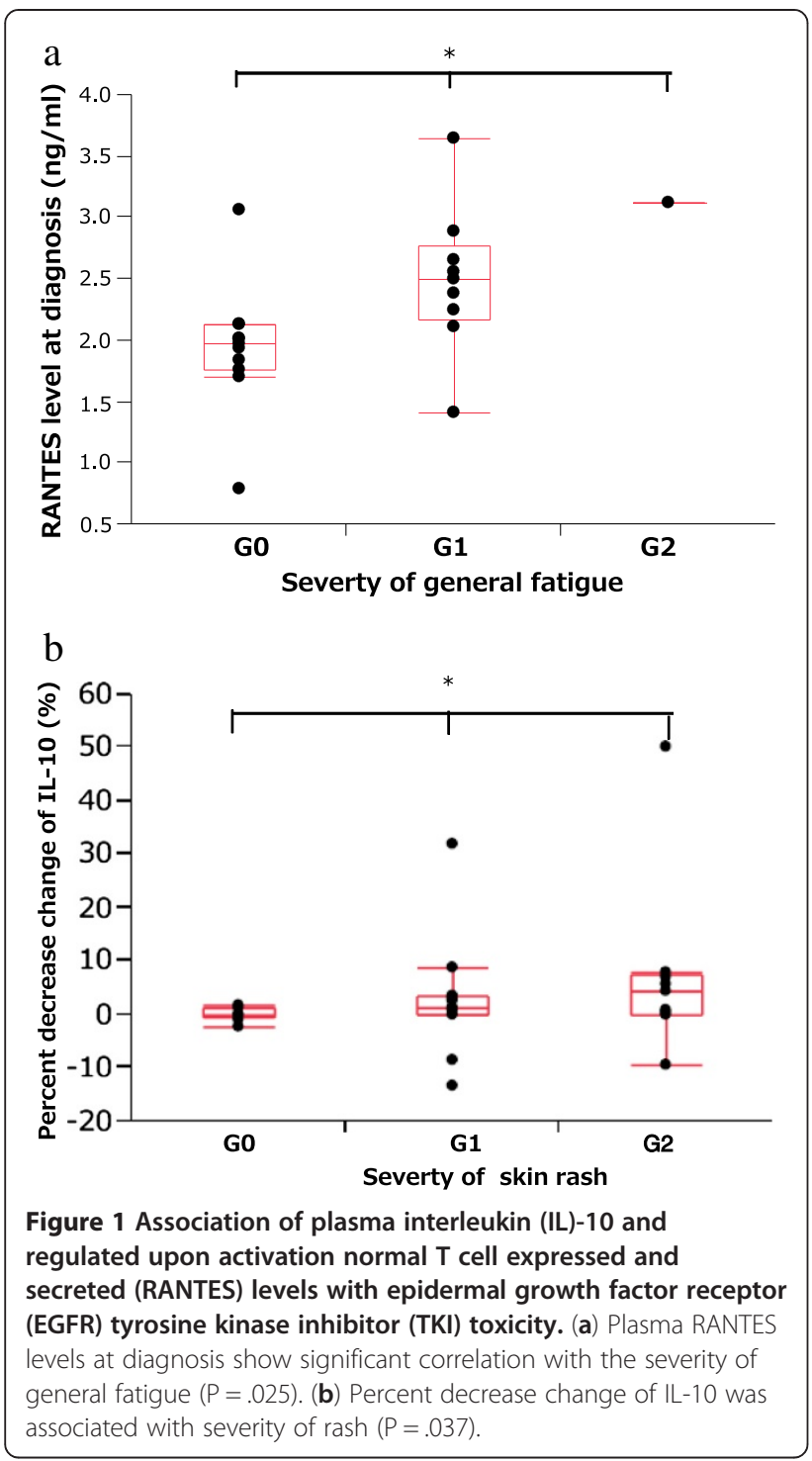

treatment was stopped for 7 of 33 patients because of PD (4 patients) and side effects (3 patients: grade 3 druginduced pneumonitis in 1 patient and grade 3 diarrhea in the other 2 patients). The median PFS and OS were 102 days (6-1442 days) and 255 days (70-1447 days), respectively.

\section{Clinical features associated with pro-inflammatory cytokine levels}

First, we analyzed the association between proinflammatory cytokine levels at diagnosis and patient characteristics (Table 2). High levels of plasma IL-8 at diagnosis showed significant positive associations with the Brinkman index $(\mathrm{P}=.0063)$. No significant associations were observed between plasma IL-10 or RANTES levels and other patient characteristics at diagnosis. Second, we analyzed the association between pro-inflammatory cytokine levels at diagnosis and adverse effects observed following EGFR-TKI treatment. High level of plasma RANTES at diagnosis was associated with the severity of general fatigue ( $\mathrm{P}=.025$, Figure 1a). Percent decrease change of plasma IL-10 was associated with severity of rash $(\mathrm{P}=.037$, Figure $1 \mathrm{~b})$. Third, we analyzed the association between pro-inflammatory cytokine levels at diagnosis and the clinical efficacy of the EGFR-TKI treatment. EGFR mutations, sex, and low level of plasma RANTES at diagnosis were significantly associated with long-term survival $(\mathrm{P}=.0044, .037$, and .046 , respectively). In a multivariate logistic regression model, EGFR mutations, sex, and low level of plasma RANTES at diagnosis were identified as significantly positive prognostic factors $\left(\mathrm{R}^{2}=.26, \mathrm{P}=.004 ; \mathrm{R}^{2}=.43, \mathrm{P}=.037 ; \mathrm{R}^{2}=.52, \mathrm{P}=.045\right.$, respectively) (Table 3$)$. No significant associations were observed between plasma pro-inflammatory cytokine levels at diagnosis and treatment responses.

\section{Plasma pro-inflammatory cytokine levels before and after EGFR-TKI treatment}

To examine the effect of EGFR-TKI treatment on the network of pro-inflammatory cytokines, we analyzed pro-inflammatory cytokine levels in the 26 patients still receiving treatment on day 30 . The plasma IL-8 $(5.48 \mathrm{pg} / \mathrm{mL}$; range, $0.49-26.13 \mathrm{pg} / \mathrm{mL})$ level on treatment day 30 was significantly lower than the level at diagnosis $(10.45 \mathrm{pg} / \mathrm{mL}$; range, $3.04-54.86 \mathrm{pg} / \mathrm{mL}$; $\mathrm{P}=.021$ ) (Figure 2). The plasma levels of other proinflammatory cytokines at diagnosis, including IL-10 $(2.16 \mathrm{pg} / \mathrm{mL}$; range $0.69-125.8 \mathrm{pg} / \mathrm{mL})$ and RANTES (2.08 $\mathrm{ng} / \mathrm{mL}$; range $0.29-3.66 \mathrm{ng} / \mathrm{mL}$ ), showed no significant change on treatment day 30 .

\section{Discussion}

We demonstrated that pro-inflammatory cytokines were affected by EGFR-TKI treatment for NSCLC. High level of plasma RANTES at diagnosis was associated with the severity of general fatigue. Low level of plasma RANTES at diagnosis was significantly associated with long-term survival by univariate and multivariate analyses. Percent decrease change of plasma IL-10 was associated with the severity of rash. Decreased level of plasma IL-8 was observed after EGFR-TKI treatment.

Tumor-derived RANTES has been detected in many clinical specimens [15]. In our study, high level of plasma RANTES at diagnosis was associated with the severity of general fatigue. Low level of plasma RANTES at diagnosis was significantly associated with long-term survival. Thus, patients with high systemic inflammation, as represented by RANTES, may experience severe general fatigue and shorter survival time. Moran et al. found a correlation between increased RANTES expression and tumor lymphocytic response in lung cancer patients 
Table 3 Step-wise multiple regression analysis between overall survival and clinical parameters

\begin{tabular}{lcccc}
\hline \multicolumn{1}{c}{ Variable } & $\begin{array}{c}\text { Standardized regression } \\
\text { coefficient }\end{array}$ & $\boldsymbol{F}$ & $\mathbf{P}$ value & $\begin{array}{c}\text { Change } \\
\text { in } \boldsymbol{R}^{\mathbf{2}}\end{array}$ \\
\hline Age & - & 0.042 & 0.840 & 0.604 \\
Sex & -108.81 & 4.883 & 0.037 & 0.431 \\
$\begin{array}{l}\text { EGFR mutation } \\
\text { Status }\end{array}$ & -164.64 & 9.954 & 0.004 & 0.258 \\
$\begin{array}{l}\text { Stage } \\
\text { IL-8 level at } \\
\text { diagnosis }\end{array}$ & - & 1.093 & 0.307 & 0.604 \\
$\begin{array}{l}\text { IL-10 level at } \\
\text { diagnosis }\end{array}$ & - & 0.001 & 0.973 & 0.604 \\
$\begin{array}{l}\text { RANTES level } \\
\text { at diagnosis }\end{array}$ & 3.30 & 3.726 & 0.066 & 0.584 \\
\hline
\end{tabular}

EGFR, Epidermal growth factor receptor; IL-8, Interleukin-8; IL-10, Interleukin-10; RANTES, Regulated upon activation normal T-cell expressed and secreted.

[17]. However, elevated RANTES expression correlated with improved survival in patients with early stage NSCLC [16]. The clinical stage of our patients was advanced, with 6 patients showing stage III and 27 showing stage IV. This may explain the completely different results of Moran et al. [17].

The determinants of tumor response and survival were assessed in patients treated with EGFR-TKIs. The multivariate Cox proportional hazards model showed that time since diagnosis and good performance status were significant predictors of survival, and survival correlated with the occurrence and severity of rash [6]. Other reports show that mutations in the EGFR are predictive and prognostic indicators in patients with NSCLC treated with erlotinib [39] and gefitinib [40]. In our study, the significant prognosis factors in the multivariate analysis were EGFR mutation status, sex, and plasma RANTES, not PS. Patient eligibility in this study required a threshold criteria of PS 0/1. Therefore, the small number of PS 2 may be the reason why PS was not a significant prognostic factor in the multivariate analysis.

Skin toxicity is the most frequently encountered toxicity in patients treated with EGFR-TKIs, and it is believed to result from direct interference of the drug function and EGFR signaling in the skin [41]. EGFR is expressed in the basal layer of the epidermis. Roles of EGFR include stimulation of epidermal growth, inhibition of differentiation, and acceleration of wound healing [41]. Inhibition of mitogen activated protein kinase (MEK), a downstream effector in the EGFR pathway, also leads to papulopustules, suggesting a mechanism-based effect. Similar inflammatory events may also account for periungual inflammation and onycholysis, whereas abnormalities in keratinocyte differentiation may explain impaired stratum corneum leading to xerosis and pruritus [42]. A recent report showed that the macrophage inflammatory protein (MIP)- $1 \beta$ levels are significantly lower in patients with skin toxicity compared to the levels in patients with no skin toxicity [43]. In atopic dermatitis, a marked increase in plasma RANTES levels accompanied by a marked decrease in IL-10 levels is observed [25]. Suppression of Th1 cells by Th2 cells seems to be abrogated by decreased IL-10 and Th2 cytokines, which may be mediated through elevated RANTES in patients with severe atopic dermatitis. In our study, percent decrease change of plasma IL-10 was associated with the severity of rash. Therefore, immune responses mediated by MIP- $1 \beta$ and plasma IL-10 may play a role in the healing process of keratinocytes damaged by EGFR-TKIs.

In our study, EGFR-TKI treatment suppressed tumor proliferation and improved PS and quality of life. At the molecular level, EGFR inhibitors suppress EGFR phosphorylation and inhibit the downstream signals of PKC and ERK, which are associated with IL-8. As a result, EGFR-TKI treatment decreased plasma IL-8 levels. We previously reported that increased adiponectin and decreased insulin levels are observed after EGFR-TKI treatment [44]. This circumstance may improve cancer related anorexia. Our 2 results suggest that EGFR-TKIs may improve cancer cachexia as a consequence of tumor shrinkage and suppress cancer related systemic inflammation.

Our study has certain limitations. The number of patients enrolled was small, and we did not evaluate the differences between the effects of cytotoxic agents and EGFR-TKIs on pro-inflammatory cytokines. The relationship between the concentrations of pro-inflammatory cytokines and tissue immunoreactivity remains to be elucidated.

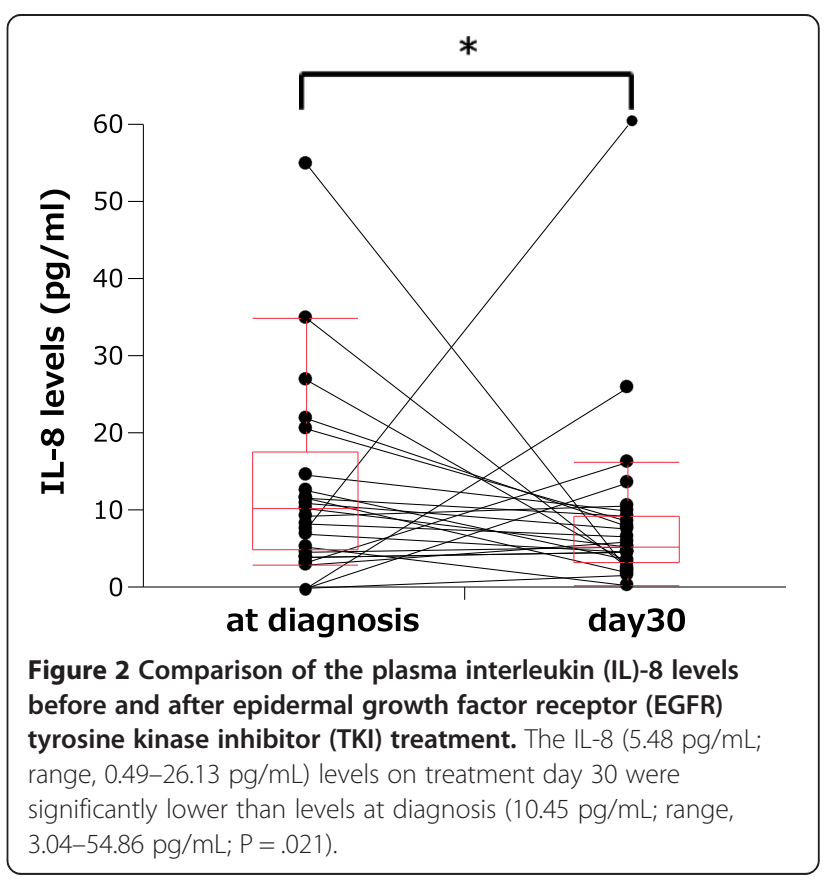




\section{Conclusion}

High level of plasma RANTES at diagnosis was associated with the severity of general fatigue. Low level of plasma RANTES at diagnosis was significantly associated with long-term survival by univariate and multivariate analyses. Percent decrease change of plasma IL-10 level was associated with the severity of rash. Decreased plasma IL-8 level was observed after EGFR-TKI treatment. The network of pro-inflammatory cytokines was affected by EGFR-TKI treatment for NSCLC. In addition, the clinical outcomes of EGFR-TKI treatment were influenced by the status of the plasma pro-inflammatory cytokines at diagnosis. Our study may provide useful information regarding patient outcomes after EGFR-TKI treatment. A large clinical trial is required to clarify these results.

\begin{abstract}
Abbreviations
IL-8: Interleukin-8; IL-10: Interleukin-10; RANTES: Regulated upon activation normal T cell expressed and secreted; EGFR-TKIs: Epidermal growth factor receptor-tyrosine kinase inhibitors; NSCLC: Non-small cell lung cancer; PKC: Protein kinases C; ERK1/2: Extracellularly related kinase 1/2; PI3K: Phosphoinositide 3-kinase; PS: Performance status; PFS: Progression free survival; OS: Overall survival; PR: Partial response; SD: Stable disease; PD: Progressive disease; MEK: Mitogen activated protein kinase; SD: Standard deviation; BMI: Body mass index; Ex: Exon; del: Deletion;

Ad: Adenocarcinoma; Sq: Squamous cell carcinoma; La: Large cell carcinoma; MIP: Macrophage inflammatory proteins.
\end{abstract}

\section{Competing interests}

The authors declare that they have no competing interests.

\section{Authors' contributions}

$\mathrm{KU}$ and TK contributed equally to this study. KU and TK were responsible for the concept and design of this review, performed literature searches, data extraction, data analysis, and drafted the manuscript. TS, KU, and TK performed the statistical analyses. YK, KU, and TK performed the multiplex protein assay. SK, MS, MN, KM, TN, NY, and KH collected clinical samples from lung cancer patients. All authors read and approved the final version of this manuscript.

\section{Authors' information}

KU, TS, TO, MN, and TN are MDs and students at the Graduate School of Medicine, Osaka City University. TK, SM, KM, and NY are MD, PhD and assistant professors at the Graduate School of Medicine, Osaka City University. SK is an MD, PhD and hospital professor at the Graduate School of Medicine, Osaka City University. YK is a PhD and technical staff member in the Department of Central Laboratory, Graduate School of Medicine, Osaka City University. $\mathrm{KH}$ is an MD, PhD, and professor at the Graduate School of Medicine, Osaka City University.

\section{Acknowledgements}

This research was partially supported by a Grant-in-Aid for Young Scientists (B), and the Ministry of Education, Culture, Sports, Science and Technology, Japan.

\section{Author details}

${ }^{1}$ Department of Respiratory Medicine, Graduate School of Medicine, Osaka City University, 1-4-3 Asahi-machi, Abeno-ku, Osaka 545-8585, Japan. 2Department of Central Laboratory, Graduate School of Medicine, Osaka City University, Osaka, Japan.

Received: 26 November 2012 Accepted: 28 March 2013 Published: 8 April 2013

\section{References}

1. Deans C, Wigmore SJ: Systemic inflammation, cachexia and prognosis in patients with cancer. Curr Opin Clin Nutr Metab Care 2005, 8:265-269.
2. Henriquet C, Gougat C, Combes A, Lazennec G, Mathieu M: Differential regulation of RANTES and IL-8 expression in lung adenocarcinoma cells. Lung Cancer 2007, 56:167-174.

3. Wakeling AE, Guy SP, Woodburn JR, Ashton SE, Curry BJ, Barker AJ, Gibson KH: ZD1839 (Iressa): an orally active inhibitor of epidermal growth factor signaling with potential for cancer therapy. Cancer Res 2002, 62:5749-5754.

4. Fukuoka M, Yano S, Giaccone G, Tamura T, Nakagawa K, Douillard JY, Nishiwaki Y, Vansteenkiste J, Kudoh S, Rischin D, Eek R, Horai T, Noda K, Takata I, Smit E, Averbuch S, Macleod A, Feyereislova A, Dong RP, Baselga J: Multi-institutional randomized phase II trial of gefitinib for previously treated patients with advanced non-small-cell lung cancer (The IDEAL 1 Trial) [corrected]. J Clin Oncol 2003, 21:2237-2246.

5. Kris MG, Natale RB, Herbst RS, Lynch TJ Jr, Prager D, Belani CP, Schiller JH, Kelly K, Spiridonidis H, Sandler A, Albain KS, Cella D, Wolf MK, Averbuch SD, Ochs JJ, Kay AC: Efficacy of gefitinib, an inhibitor of the epidermal growth factor receptor tyrosine kinase, in symptomatic patients with non-small cell lung cancer: a randomized trial. JAMA 2003, 290:2149-2158.

6. Perez-Soler R, Chachoua A, Hammond LA, Rowinsky EK, Huberman M, Karp D, Rigas J, Clark GM, Santabarbara P, Bonomi P: Determinants of tumor response and survival with erlotinib in patients with non-small-cell lung cancer. J Clin Oncol 2004, 22:3238-3247.

7. Luppi F, Longo AM, de Boer WI, Rabe KF, Hiemstra PS: Interleukin-8 stimulates cell proliferation in non-small cell lung cancer through epidermal growth factor receptor transactivation. Lung Cancer 2007, 56:25-33.

8. Akca H, Tani M, Hishida T, Matsumoto S, Yokota J: Activation of the AKT and STAT3 pathways and prolonged survival by a mutant EGFR in human lung cancer cells. Lung Cancer 2006, 54:25-33.

9. Zhang $Y$, Wang $L$, Zhang $M$, Jin $M$, Bai $C$, Wang $X$ : Potential mechanism of interleukin-8 production from lung cancer cells: an involvement of EGF-EGFR-PI3K-Akt-Erk pathway. J Cell Physiol 2012, 227:35-43.

10. Lu ZJ, Zhou Y, Song Q, Qin Z, Zhang H, Zhou YJ, Gou LT, Yang JL, Luo F: Periplocin inhibits growth of lung cancer in vitro and in vivo by blocking AKT/ERK signaling pathways. Cell Physiol Biochem 2010, 26:609-618.

11. Bader AG, Kang S, Zhao L, Vogt PK: Oncogenic PI3K deregulates transcription and translation. Nat Rev Cancer 2005, 5:921-929.

12. Yamamoto H, Shigematsu $H$, Nomura M, Lockwood WW, Sato M, Okumura N, Soh J, Suzuki M, Wistuba II, Fong KM, Lee H, Toyooka S, Date H, Lam WL, Minna JD, Gazdaret AF: PIK3CA mutations and copy number gains in human lung cancers. Cancer Res 2008, 68:6913-6921.

13. Janeway CA Jr: The immune system evolved to discriminate infectious nonself from noninfectious self. Immunol Today 1992, 13:11-16.

14. Borczuk AC, Papanikolaou N, Toonkel RL, Sole M, Gorenstein LA, Ginsburg ME, Sonett JR, Friedman RA, Powell CA: Lung adenocarcinoma invasion in TGFbetaRIl-deficient cells is mediated by CCL5/RANTES. Oncogene 2008, 27:557-564.

15. Niwa $Y$, Akamatsu $H$, Niwa H, Sumi H, Ozaki Y, Abe A: Correlation of tissue and plasma RANTES levels with disease course in patients with breast or cervical cancer. Clin Cancer Res 2001, 7:285-289.

16. Toonkel RL, Borczuk AC, Powell CA: Tgf-beta signaling pathway in lung adenocarcinoma invasion. J Thorac Oncol 2010, 5:153-157.

17. Moran CJ, Arenberg DA, Huang CC, Giordano TJ, Thomas DG, Misek DE, Chen G, lannettoni MD, Orringer MB, Hanash S, Beer DG: RANTES expression is a predictor of survival in stage I lung adenocarcinoma. Clin Cancer Res 2002, 8:3803-3812.

18. Koivunen J, Aaltonen V, Peltonen J: Protein kinase C (PKC) family in cancer progression. Cancer Lett 2006, 235:1-10.

19. Mackay HJ, Twelves CJ: Protein kinase C: a target for anticancer drugs? Endocr Relat Cancer 2003, 10:389-396.

20. Blobe GC, Sachs CW, Khan WA, Fabbro D, Stabel S, Wetsel WC, Obeid LM, Fine RL, Hannun YA: Selective regulation of expression of protein kinase $\mathrm{C}(\mathrm{PKC})$ isoenzymes in multidrug-resistant MCF-7 cells. Functional significance of enhanced expression of PKC alpha. J Biol Chem 1993, 268:658-664.

21. Burgering BM, de Vries-Smits AM, Medema RH, van Weeren PC, Tertoolen $L G$, Bos JL: Epidermal growth factor induces phosphorylation of extracellular signal-regulated kinase 2 via multiple pathways. $\mathrm{Mol} \mathrm{Cell}$ Biol 1993, 13:7248-7256.

22. Stewart JR, O'Brian CA: Protein kinase C-\{alpha\} mediates epidermal growth factor receptor transactivation in human prostate cancer cells. Mol Cancer Ther 2005, 4:726-732. 
23. Mosser DM, Zhang $X$ : Interleukin-10: new perspectives on an old cytokine. Immunol Rev 2008, 226:205-218.

24. Wang YC, Sung WW, Wu TC, Wang L, Chien WP, Cheng YW, Chen CY, Shieh $\mathrm{SH}$, Lee $\mathrm{H}$ : Interleukin-10 haplotype may predict survival and relapse in resected non-small cell lung cancer. PLoS One 2012, 7:e39525.

25. Niwa Y: Elevated RANTES levels in plasma or skin and decreased plasma IL-10 levels in subsets of patients with severe atopic dermatitis. Arch Dermatol 2000, 136:125-126.

26. Giacomelli L, Gianni W, Belfiore C, Gandini O, Repetto L, Filippini A, Frati L, Agliano AM, Gazzaniga P: Persistence of epidermal growth factor receptor and interleukin 10 in blood of colorectal cancer patients after surgery identifies patients with high risk to relapse. Clin Cancer Res 2003, 9:2678-2682.

27. Masuya D, Huang C, Liu D, Kameyama K, Hayashi E, Yamauchi A, Kobayashi S, Haba R, Yokomise $H$ : The intratumoral expression of vascular endothelial growth factor and interleukin-8 associated with angiogenesis in nonsmall cell lung carcinoma patients. Cancer 2001 92:2628-2638

28. De Boer WI: Cytokines and therapy in COPD: a promising combination? Chest 2002, 121:209S-218S

29. Subauste MC, Proud D: Effects of tumor necrosis factor-alpha, epidermal growth factor and transforming growth factor-alpha on interleukin-8 production by, and human rhinovirus replication in, bronchial epithelial cells. Int Immunopharmacol 2001, 1:1229-1234.

30. Richter A, O'Donnell RA, Powell RM, Sanders MW, Holgate ST, Djukanovic R, Davies DE: Autocrine ligands for the epidermal growth factor receptor mediate interleukin-8 release from bronchial epithelial cells in response to cigarette smoke. Am J Respir Cell Mol Biol 2002, 27:85-90.

31. Lee YC, Lin HH, Hsu CH, Wang CJ, Chiang TA, Chen JH: Inhibitory effects of andrographolide on migration and invasion in human non-small cell lung cancer A549 cells via down-regulation of PI3K/Akt signaling pathway. Eur J Pharmacol 2010, 632:23-32.

32. Su JC, Lin KL, Chien CM, Tseng CH, Chen YL, Chang LS, Lin SR: Naphtho [1,2-b]furan-4,5-dione inactivates EGFR and PI3K/Akt signaling pathways in human lung adenocarcinoma A549 cells. Life Sci 2010, 86:207-213.

33. Christensen JG, Vincent PW, Klohs WD, Fry DW, Leopold WR, Elliott WL: Plasma vascular endothelial growth factor and interleukin-8 as biomarkers of antitumor efficacy of a prototypical erbB family tyrosine kinase inhibitor. Mol Cancer Ther 2005, 4:938-947.

34. Perrotte P, Matsumoto T, Inoue K, Kuniyasu H, Eve BY, Hicklin DJ, Radinsky R, Dinney CP: Anti-epidermal growth factor receptor antibody C225 inhibits angiogenesis in human transitional cell carcinoma growing orthotopically in nude mice. Clin Cancer Res 1999, 5:257-265.

35. Nagai Y, Miyazawa H, Huqun, Tanaka T, Udagawa K, Kato M, Fukuyama S, Yokote A, Kobayashi K, Kanazawa M, Hagiwara K: Genetic heterogeneity of the epidermal growth factor receptor in non-small cell lung cancer cell lines revealed by a rapid and sensitive detection system, the peptide nucleic acid-locked nucleic acid PCR clamp. Cancer Res 2005, 65:7276-7282.

36. Eisenhauer EA, Therasse P, Bogaerts J, Schwartz LH, Sargent D, Ford R, Dancey J, Arbuck S, Gwyther S, Mooney M, Rubinstein L, Shankar L, Dodd L, Kaplan R, Lacombe D, Verweijet J: New response evaluation criteria in solid tumours: revised RECIST guideline (version 1.1). Eur J Cancer 2009, 45:228-247.

37. Trotti A, Colevas AD, Setser A, Rusch $V$, Jaques D, Budach $V$, Langer $C$, Murphy B, Cumberlin R, Coleman CN, Rubin P: CTCAE v3.0: development of a comprehensive grading system for the adverse effects of cancer treatment. Semin Radiat Oncol 2003, 3:176-81.

38. Yu H, Rohan T: Role of the insulin-like growth factor family in cancer development and progression. J Natl Cancer Inst 2000, 92:1472-1489.

39. Eberhard DA, Johnson BE, Amler LC, Goddard AD, Heldens SL, Herbst RS, Ince $W L$, Janne PA, Januario $T$, Johnson DH, Klein P, Miller VA, Ostland MA, Ramies DA, Sebisanovic D, Stinson JA, Zhang YR, Seshagiri S, Hillan KJ: Mutations in the epidermal growth factor receptor and in KRAS are predictive and prognostic indicators in patients with non-small-cell lung cancer treated with chemotherapy alone and in combination with erlotinib. J Clin Oncol 2005, 23:5900-5909.

40. Chou TY, Chiu CH, Li LH, Hsiao CY, Tzen CY, Chang KT, Chen YM, Perng RP, Tsai SF, Tsai CM: Mutation in the tyrosine kinase domain of epidermal growth factor receptor is a predictive and prognostic factor for gefitinib treatment in patients with non-small cell lung cancer. Clin Cancer Res 2005, 11:3750-3757
41. Lacouture ME, Melosky BL: Cutaneous reactions to anticancer agents targeting the epidermal growth factor receptor: a dermatology-oncology perspective. Skin Therapy Lett 2007, 12:1-5.

42. Lacouture ME, Lai SE: The PRIDE (Papulopustules and/or paronychia, Regulatory abnormalities of hair growth, Itching, and Dryness due to Epidermal growth factor receptor inhibitors) syndrome. $\mathrm{Br} J$ Dermatol 2006, 155:852-854

43. Kimura H, Kasahara K, Sekijima M, Tamura T, Nishio K: Plasma MIP-1beta levels and skin toxicity in Japanese non-small cell lung cancer patients treated with the EGFR-targeted tyrosine kinase inhibitor, gefitinib. Lung Cancer 2005, 50:393-399.

44. Umekawa K, Kimura T, Kudoh S, Suzumura T, Oka T, Nagata M, Mitsuoka S, Matsuura K, Yoshimura N, Kira Y, Hirata K: Reaction of plasma adiponectin level in non-small cell lung cancer patients treated with EGFR-TKIs. Osaka City Med J 2012, 59. in press.

doi:10.1186/1756-0500-6-139

Cite this article as: Umekawa et al:: Plasma RANTES, IL-10, and IL-8 levels in non-small-cell lung cancer patients treated with EGFR-TKIs. BMC Research Notes 2013 6:139.

\section{Submit your next manuscript to BioMed Central and take full advantage of:}

- Convenient online submission

- Thorough peer review

- No space constraints or color figure charges

- Immediate publication on acceptance

- Inclusion in PubMed, CAS, Scopus and Google Scholar

- Research which is freely available for redistribution 